\title{
The Contribution of Tanzanian National Parks in Controlling the Vectors of Sleeping Sickness
}

\author{
Epaphras A. Muse', Inyasi Lejora ${ }^{2}$, James Wakibara ${ }^{3}$, Morris Kilewo ${ }^{3}$, Idrissa S. Chuma ${ }^{4}$, \\ Emilian Kihwele4, Damari Samwel2 ${ }^{2}$, Abel Mtui ${ }^{3}$, Calvin Sindato ${ }^{5}$, Imna Malele ${ }^{6 *}$ \\ ${ }^{1}$ Ruaha National Park, Iringa, Tanzania \\ ${ }^{2}$ Tanzania National Parks Headquarters, Arusha, Tanzania \\ ${ }^{3}$ Tarangire National Park, Manyara, Tanzania \\ ${ }^{4}$ Serengeti National Park, Mara, Tanzania \\ ${ }^{5}$ National Institute for Medical Research, Tabora, Tanzania \\ ${ }^{6}$ Vector \& Vector Borne Diseases Research Institute, Tanga, Tanzania \\ Email: ${ }^{*}$ maleleimna@gmail.com
}

Received 28 April 2015; accepted 11 July 2015; published 15 July 2015

Copyright (C) 2015 by authors and Scientific Research Publishing Inc.

This work is licensed under the Creative Commons Attribution International License (CC BY). http://creativecommons.org/licenses/by/4.0/

(c) (i) Open Access

\section{Abstract}

This paper summarises efforts to control Sleeping sickness [Human African Trypanosomiasis (HAT)] by Tsetse flies and Trypanosomiaisis $(T \& T)$ control for the 7 consecutive years although started a decade ago in Tanzania National Parks (TANAPA). These efforts are critical for curbing HAT incidences and HAT epidemics. HAT cases have had profound negative impacts on human health, affecting local residents and international travel as well as tourism industry resulting into human and animal health burden and reduction in tourism income. Understanding the current efforts is essential in the proper planning and decision making on developing effective control strategy against $\mathrm{T} \& \mathrm{~T}$ control. In this paper, we summarize the recent efforts in the control of $\mathrm{T} \& \mathrm{~T}$ in National Parks and discuss the constraints faced. The information will enable TANAPA and other concerned authorities to make informed decision on optimal ways of controlling HAT in National Parks. The results show that much control efforts have so far concentrated in Serengeti, Ruaha, Tarangire and Katavi National Parks where tsetse fly challenges are high. A total 21,143 (average 3020) Insecticide Treated Targets (ITT) were deployed in different areas in the parks and 82,899 (average 20,725) cars entering these parks were sprayed from $2007 / 2008$ to $2014 / 2015$ and $2007 / 2008$ to 2010/2011 respectively. Deployed ITTs lead to a drastic reduction of FTDs of the two dominant tsetse species to 1.3 and 1.4 of G. swynnertoni and G. pallidipes respectively, and the decline was significant at $P=0.011$. The major challenges faced include tsetse re-invasion in controlled areas; resurgence of HAT cases when control efforts are relaxed, ITT maintenance and in-

\footnotetext{
${ }^{*}$ Corresponding author.
}

How to cite this paper: Muse, E.A., Lejora, I., Wakibara, J., Kilewo, M., Chuma, I.S., Kihwele, E., Samwel, D., Mtui, A., Sindato, C. and Malele, I. (2015) The Contribution of Tanzanian National Parks in Controlling the Vectors of Sleeping Sickness. Open Journal of Ecology, 5, 306-314. http://dx.doi.org/10.4236/oje.2015.57025 
adequate health education programs. The control strategy should be continuous and scaled up as failure to implement an effective and sustainable system for HAT control will increase the risk of new epidemic that would impede tourism development.

\section{Keywords}

\section{Tsetse Fly, Insecticides, Targets, Sleeping Sickness, Tanzania}

\section{Introduction}

Tanzania National Parks (TANAPA) has a number of parks with suitable tsetse habitat (vegetations) which supports tsetse fly infestation. Tsetse flies belong to the genus Glossina and family Glossinadae. The genus Glossina includes species of the Fusca group that mainly inhabit forests whereas the Palpalis group inhabit the riverine vegetation. The Morsitans group inhabit mainly the savannah vegetation [1] [2]. In Tanzania, the Morsitans is the dominant group and is found almost throughout the country where the habitat support tsetse survival; whereas the Palpalis group is restricted around the Lake shore of Lake Victoria (G. f. fuscipes) and Lake shore of Tanganyika (G. f. fuscipes and G. f. martini).

Studies that were carried out mainly in Serengeti and Tarangire National Parks showed that the tsetse dominant species in these parks were Glossina swynnertoni and G. pallidipes [3]-[5]. G. swynnertoni is limited mainly in bushy areas and G. pallidipes is mainly in the thickets and open areas. The two species including $G$. brevipalpis, G. m. morsitans and G. longipennis transmit animal and human trypanosomiasis caused by four major salivarian trypanosomes namely T. congolense, T. vivax and T. brucei brucei for animals and T.b. rhodesiense for humans [4] [6]-[9].

Sleeping sickness or HAT in East Africa is caused by Trypanosoma brucei rhodesiense which cause acute form of the disease. The impacts of the disease are immense as a cause of morbidity and mortality in animal and human populations. It also leads to economic losses as it affects tourist arrivals. Worldwide records show that from 1995 to 2010 a total of 75 international HAT cases involved travellers that had once visited African countries (NIMR unpubl.; TANAPA unpubl.; [10]). Strikingly, more than half (57.3\%) of these cases had visited Tanzanian Parks [10].

In Tanzania, a total of 2897 HAT cases were diagnosed between 1995 and 2010 (NIMR, 2010). Records also show that six residents contracted HAT between 2001 and 2008 in Serengeti National Park of which two died (TANAPA unpubl.). Besides, there have been complaints of tsetse bites by visitors and park's residents in Tanzania parks over the years. The data revealed a continued high public health risk due HAT transmission from tsetse flies to both local residents and international tourists visiting national parks [11].

The continued high risk of HAT in the prime Tanzanian tourist's destinations; posse high threat to the competing tourism industry in the Eastern African region and the world at large. Given the fact that tourism is one of the leading economic sectors in Tanzania contributing between 17.5\% and 25\% of GDP and foreign currency, respectively [12] tourism industry needs appropriate attention to address the HAT risk particularly in National Parks. If tourist arrivals decline, the tourism related revenue will definitely drop. The political and socio-economic implications of HAT to Tanzanian tourism industry and the economy as a whole are therefore huge and multifaceted.

In recognition of HAT problem to individuals living within the parks, adjacent areas and tourism industry, there have been some ongoing local control efforts in Tanzanian National Parks for years [13]. Although, TANAPA has been involved in controlling tsetse flies since 2002, the available information is fragmented.

This paper therefore consolidates TANAPA's effort of controlling HAT as a tool for informed future work on HAT control within the Parks and in similarly affected protected areas elsewhere. HAT control in Tanzania will definitely improve tourism industry and local livelihoods in infested areas and contribute towards the attainment of Millennium Development Goals and make Tanzanian parks a safe tourist destination.

\section{HAT Control Approaches}

In general tsetse flies are active during daytime and are attracted from a distance by blue colour however, tsetse 
will land on a black surface and horizontal oblongs are preferred more than the vertical ones (NRI) and also are attracted to the motion of vehicles [14]-[17]. The attraction to motion of vehicles is what has necessitated spraying vehicles with Deltamethrin.

\section{Insecticide Treated Targets (ITTs)}

The main HAT control approach has been to use Insecticide Treated Targets (ITT). The ITT's are rectangular $(1.0 \times 1.0 \mathrm{~m}$ or $1.5 \times 1.0 \mathrm{~m})$ black-blue-black or blue-black-blue cloth (Figure 1), treated with Glossinex 200 SC $^{\circledR}$ (20\% Deltamethrin) or Decatix ${ }^{\circledR}$ (5\% Deltamethrin). The targets are fully soaked in insecticide containers for about 10 minutes; sometimes the insecticide is applied on the black portion only where tsetse are elicited to prefer to land. This selective application allows the amount of insecticide required to be reduced. After treatment, the targets are spread under the shade for complete dryness and then wrapped in plastic bags ready for field deployment. Deployed ITTs are also baited with acetone as a fly attractant at a rate of $20 \mathrm{ml}$ per target to lure flies to land on the ITTs. Retreatment is done at an interval of about six months during the dry season and 2 - 4 months during the wet season. The targets are often deployed in tsetse habitat mainly along the tourist circuits/roads and Park staff residential quarters, lodges, camping sites, picnic sites and scenery viewing points. The targets are placed about $100 \mathrm{~m}$ apart.

\section{Vehicles Spraying}

In addition to the ITT's, vehicles entering and travelling in the Parks are sprayed with insecticides to serve as moving targets. This serves to control flies in areas without cloth targets and especially to attract flies that follow moving objects. The lower half of a vehicle is sprayed with approximately [4 $\mathrm{ml}$ of Glossinex ${ }^{\circledR}$ mixed with water in a $16 \mathrm{~L}$ using (i.e. $0.25 \mathrm{ml} / \mathrm{L}$ )] using hand held pumps.

\section{Monitoring Tsetse Density}

Monitoring tsetse control is essential to decide upon the most effective control strategy. Among the different types of the tsetse fly traps available, the preferred traps by TANAPA are Biconical [18] and NGU [19]. Retaining traps particularly biconical are interspaced with ITTs at every $200 \mathrm{~m}$ in order to monitor changes in tsetse density and distribution over time. This is essential as one measure of the effectiveness of HAT control efforts being undertaken by targeting the vector. Monitoring traps are emptied after every 24 hours during the pre control phase for two days and or after every one week during the control period for six month. However for comparison purposes, data from the control phase was collected for two days.

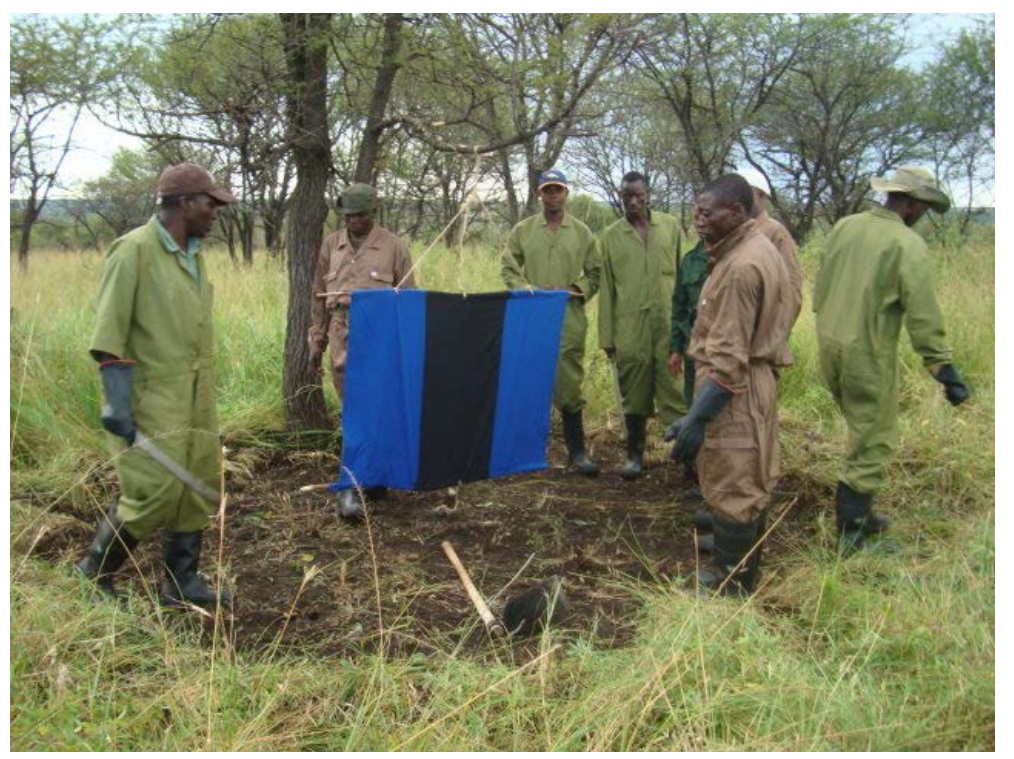

Figure 1. Insecticide Treated Target deployment in the field. 
Before the implementation of the control program by ITTs, trapped tsetse were sorted out into respective species and recorded [20]. The recorded information gave the type of species found in the area, and the apparent densities of each species

Although tsetse traps can be used for tsetse control especially when treated with insecticide, traps in the parks are only used for monitoring changes in tsetse density and distribution and also when there is a need for assessment of the performance or effectiveness of the targets.

\section{Monitoring and Capacity Strengthening of HAT Diagnosis}

Besides tsetse fly density profiles another important proxy indicator of the effectiveness of the IIT is the reduced human cases of HAT. Capacity strengthening in the diagnosis of HAT had been ongoing especially in Serengeti National Park that had reported largest number of human cases both in tourists and local residents. This is being implemented in collaboration with the ministry of Health and Social Welfare (MoHSW) in Tanzania. It includes training for diagnosis and management of HAT cases in the health facilities within the parks, adjacent to the parks as well as the referral hospitals along the tsetse belt in the country where most tourists had been seeking general health care and specific health care whenever HAT transmission was suspicious. Furthermore, TANAPA had maintained the availability of consumables/reagents and equipments for the diagnosis and management of HAT in the parks.

TANAPA in collaboration with the MoHSW has conducted regular surveillance of HAT in individuals working within the parks for prompt appropriate actions. The drugs for managing the cases of HAT are supplied under the support of WHO and therefore the patients incur no cost related to drugs. Additional activities that had been carried out during the regular surveillance of HAT included the health education. Other activities in collaborations with the Ministry of Livestock and Fisheries Development include monitoring the disease prevalence in domesticated host which have been found to habour African Trypanosomiasis causative parasites [21] [22].

\section{Data Sources}

Data on tsetse control and thus HAT, are mainly from 5 Tanzanian National Parks of Serengeti, Ruaha, Tarangire, Katavi and Mikumi (Figure 2) spanning 2007/2008-2014/2015. This is because most HAT control activities are conducted in these Parks compared to the remaining nine parks. Information on vector control was gathered from both regular TANAPA official reports and from published material, supplemented by informal interviews with key informants (Veterinarians and Ecologists) responsible for HAT control.

\section{Results}

A total of 10 biconical traps were deployed before the initiation of the control program at two sites for two days and flies collected every day. The apparent density for flies during the control phase for both species declined to a significance of $\mathrm{P}=0.011$. The apparent density for flies during the pre control as well as the control phase is as indicated in Table 1.

During the period 2007-2013 a total of 21143ITT were deployed in the eight National Parks. However, deployment was highest in Serengeti followed by Ruaha and Katavi National Park, Tarangire and Mikumi in descending order. The mean annual ITTs deployment for each park is shown in Table 2 in brackets. Ruaha deployed about 1048 ITTs followed by 868 in Serengeti (Table 2). More vehicles were also sprayed in Serengeti, Tarangire and Katavi in descending order (Table 3).

\section{Discussion}

Vector control activities were consistent between 2007/2008 to 2010/2011 however from 2012 there was a declining trend on the efforts for controlling tsetse. We speculate the sudden rise in HAT control effort in those years was in part due to a direct response to the increased tourism activities in the Parks, especially game viewing areas but also due to more cases of HAT that were reported outside the country [10].

The root of interventions against sleeping sickness is early detection and treatment of HAT cases, fly vector control and animal reservoir management [16] [23] [24]. TANAPA has routinely been engaged in vector control 


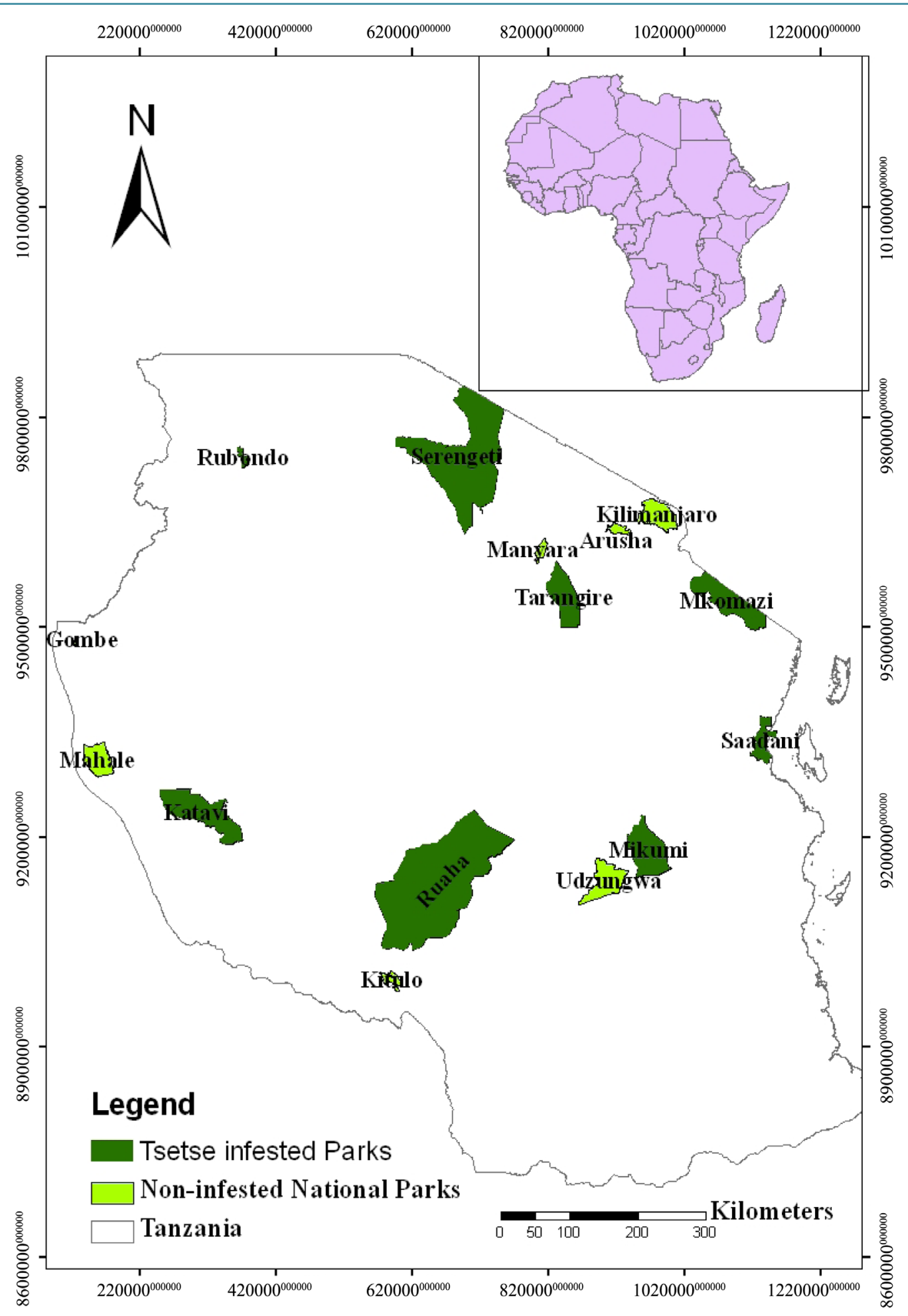

Figure 2. Tanzania National Parks.

through deployment of ITT since 2002 [13] as was advised through the study conducted in and around Serengeti ecosystem thereby reducing tsetse fly bites. In addition these ITTs have proved to control tsetse flies in other studies elsewhere [25].

This paper reports on tsetse control initiatives that have been ongoing since 2007 to 2014 . The control efforts 
Table 1. Tsetse numbers and densities in brackets before the deployment of ITTs.

\begin{tabular}{ccc}
\hline Blocks & G. swynnertoni $($ FTD $)$ & G. pallidipes (FTD) \\
\hline Pre control phase A & $733 / 10$ traps $/ 2$ day $=36.7$ & $592 / 10$ trap $/ 2$ day $=29.6$ \\
Pre control phase B & $547 / 10 \mathrm{~T} / 2 \mathrm{D}=27.4$ & $392 / 10 / 2 \mathrm{D}=19.6$ \\
Control Phase & $26 / 10 / 2 \mathrm{~d}=1.3$ & $27 / 10 / 2 \mathrm{~d}=1.4$ \\
\hline
\end{tabular}

NB: FTD = Flies per Trap per Day.

Table 2. Deployment of ITTs 2007/2008 to 2014/2015.

\begin{tabular}{ccccccccc}
\hline National Park & $\mathbf{2 0 0 7 / 2 0 0 8}$ & $\mathbf{2 0 0 8 / 2 0 0 9}$ & $\mathbf{2 0 1 0 / 2 0 1 1}$ & $\mathbf{2 0 1 1 / 2 0 1 2}$ & $\mathbf{2 0 1 2 / 2 0 1 3}$ & $\mathbf{2 0 1 3 / 2 0 1 4}$ & $\mathbf{2 0 1 4 / 2 0 1 5} \begin{array}{c}\text { TOTAL and } \\
\text { averages in brackets }\end{array}$ \\
\hline Serengeti & 1769 & 1918 & 708 & 0 & 1209 & 477 & 0 & $6081(868)$ \\
Ruaha & 1550 & 1670 & 1200 & 1300 & 1000 & 423 & 196 & $7339(1048)$ \\
Katavi & 0 & 380 & 2035 & 0 & 38 & 490 & 391 & $3334(476)$ \\
Tarangire & 0 & 387 & 400 & 0 & 778 & 547 & 275 & $2387(341)$ \\
Mikumi & 0 & 0 & 1500 & 0 & 400 & 102 & 0 & $2002(286)$ \\
Total & $\mathbf{3 3 1 9}$ & $\mathbf{4 3 5 5}$ & $\mathbf{5 8 4 3}$ & $\mathbf{1 3 0 0}$ & $\mathbf{3 4 2 5}$ & $\mathbf{2 0 3 9}$ & $\mathbf{8 6 2}$ & $\mathbf{2 1 1 4 3 ( 3 0 2 0 )}$ \\
\hline
\end{tabular}

Table 3. Vehicle hand spraying 2007/2008 to 2010/2011.

\begin{tabular}{|c|c|c|c|c|c|}
\hline National Park & $2007 / 2008$ & $2008 / 2009$ & $2009 / 2010$ & 2010/2011 & TOTAL and averages in brackets \\
\hline Serengeti & 0 & 11,403 & 10,690 & 41,465 & $63,558(15,890)$ \\
\hline Tarangire & 2340 & 2108 & 2567 & 5300 & 12,315 (3079) \\
\hline Katavi & 1175 & 693 & 2710 & 2448 & 7026 (1757) \\
\hline Total & 3515 & 14,204 & 15,967 & 49,213 & $82,899(20,725)$ \\
\hline
\end{tabular}

have been concentrated in the tsetse highly infested areas in Serengeti, Ruaha, Tarangire and Katavi national parks in addition to other national parks. This paper summarizes the effort by TANAPA tsetse and HAT control efforts for the past 7 years.

Although the bait technologies is advantageous over other technologies which include being environmentally benign and affordability, the drawbacks of the method is that of regular requirements for maintenance and its failure to eradicate residual tsetse populations. The effectiveness of targets as control tools depends on their rate of removal of flies from the existing tsetse fly populations. The ITT control strategy is an important component for controlling the vector and in turn prevents trypanosomiasis epidemics.

Although tsetse control in TANAPA started a decade ago, the tsetse challenges is still high, this may be attributed by the fact that there is re-invasion from areas that tsetse have not been controlled. Also the environment and habitats in the parks support thriving of tsetse due to the availability of stable vegetation for resting and breeding; abundant supply of blood meal from wild animals. What need to be done is to reduce tsetse population strategically (i.e. around offices, camping sites, houses, roads etc.) so that to minimize tsetse-man contacts and thus risks of contracting HAT. Study done in 2011 showed that there are hot spots and breeding areas in the parks which act as a source of tsetse to other areas. Hence efforts need to continue in order to bring down tsetse populations especially the non teneral flies in order to minimize risks of HAT transmissions. The extensive protected areas are tsetse breeding hot spots and act as source of tsetse re-envisions for the neighbouring controlled areas in communities [26]. These areas include game reserves, game controlled areas such that even if tsetse are controlled in national parks areas, still there will be re-invasion from other protected areas with minimal tsetse control programs. Hence tsetse control should not be restricted to national parks only rather control should be extended to all tsetse infested areas.

The tsetse control strategy played a significant role in the control of previous HAT outbreaks to tourists, park 
staff and surrounding communities in northern parks. This is one of the major achievements by parks control efforts.

Other tsetse control measures like use of fly repellents plus avoiding dark bluish and black coloured clothing will assist to minimize tsetse-man contact [27]-[29]. Other measures should include occasional monitoring of the level of human infective trypanosomes in tsetse (Xenomonitoring) for guided deployment of ITTs once proven that there is an increased level of human infective trypanosomes in a certain localized tsetse population [30].

With respect to early detection and treatment of HAT cases there has been occasional human screening carried out by health authorities in collaboration with TANAPA and the National Medical Research Institute (NMRI) mostly in reaction to the HAT reported cases [21] [31]. These human surveys were conducted with the aim of detecting and treating HAT cases in Serengeti and Tarangire.

Although recent studies show a decrease in tsetse belt due to the changes in land use as main reason [26]; the factors contributing to the decrease does not apply to the protected areas.

\section{Way Forward}

Long lasting cloths and insecticides formulations may help in reducing the challenges of tsetse bites, and continued deployment of ITTs and re-spraying of targets and vehicles. The formulations also should consider ways of minimizing the reduction of insecticide on the targets due to rain, sunlight, wind and dust that reduces lethal effects to the flies.

Other tsetse control challenges are adequate health education programs/campaigns in protected areas and resources constraints to be utilized to fully embrace the control of tsetse both in terms of man power and funds to implement control programs. The use of ITTs is usually known to be labour intensive [32] however concentration and intensification of tsetse control in tsetse hot spots should be the way to continue reducing the vector population.

Considering tsetse breeding hotspots, efficient tsetse control can only be achieved by combined efforts between authorities responsible for protected areas including TANAPA, the Wildlife Division in the Ministry of Natural resources and Local governments through policy formulations, funding, coordination and regulation and enforcement of policy and laws related to implementation of tsetse control plans. Local communities should also be involved in tsetse control activities in their communities especially those that are near protected areas to ensure sustainability of the control efforts. It is through mutually and harmonized tsetse control efforts that these flies will be controlled from the protected areas sustainably over the decades to come and ensure elimination of the HAT in future; to make Tanzanian National parks a safe tourist destination both for park residents and tourists.

\section{Conclusion}

Deployed ITTs lead to a drastic reduction of FTDs of the two dominant tsetse species to 1.3 and 1.4 of G. swynnertoni and G. pallidipes respectively, and the decline was significant at $\mathrm{P}=0.011$. Continued application of ITTs in protected game areas supplemented with other approaches like vehicle spraying and awareness to staff and people/tourists entering the parks will significantly lead to the reduction of HAT cases associated with Tanzania National Parks.

\section{Acknowledgements}

We are grateful to the Director General Tanzania National Parks. We extend our appreciation to the Chief Park wardens from different parks for coordinating and facilitating tsetse control efforts. The information included in this paper has been collected from different parks and Ecologists and Veterinarians' efforts are highly valued.

\section{Conflict of Interest Statement}

The authors declare that the research was conducted in the absence of any commercial or financial relationships that could be construed as a potential conflict of interest.

\section{References}

[1] Ford, J. and Katondo, K.M. (1977) Maps of Tsetse Fly (Glossina) Distribution in Africa 1973, According to Sub-Ge- 
neric Groups at a Scale of 1:5,000,000. Bulletin of Animal health and Production in Africa, 15, 187-193.

[2] Jordan, A.M. (1986) Trypanosomiasis Control and African Rural Development. Longman Inc., New York.

[3] Malele, I.I., Kinung’hi, S.M., Nyingilili, H.S., Matemba, L.E., Sahani, J.K., Mlengeya, T.D.K., Wambura, M. and Kibona, S.N. (2007) Glossina Dynamics in and around the Sleeping Sickness Endemic Serengeti Ecosystem of Northwestern Tanzania. Journal of Vector Ecology, 32, 263-268. http://dx.doi.org/10.3376/1081-1710(2007)32[263:GDIAAT]2.0.CO;2

[4] Adams, E.R., Hamilton, P.B., Malele, I.I. and Gibson, W.C. (2008) The Identification, Diversity and Prevalence of Trypanosomes in Field Caught Tsetse in Tanzania Using ITS-1 Primers and Fluorescent Fragment Length Barcoding. Infection, Genetics and Evolution, 8, 439-444. http://dx.doi.org/10.1016/j.meegid.2007.07.013

[5] Auty, H., Picozzi, K., Malele, I.I., Torr, S., Cleaveland, S. and Welburn, S. (2012) Incorporating Molecular Data for Epidemiological Inference: Assessing the Prevalence of Trypanosoma brucei rhodesiense in Tsetse Populations in Serengeti, Tanzania. PLOS Neglected Tropical Diseases, 6, e1501. http://dx.doi.org/10.1371/journal.pntd.0001501

[6] Jelinek, T., Bisoffi, Z., Bonazzi, L., van Thiel, P., Bronner, U. and De Frey, A. (2002) Cluster of African Trypanosomiasis in Travelers to Tanzanian National Parks. Emerging Infectious Diseases, 8, 634-635. http://dx.doi.org/10.3201/eid0806.010432

[7] Malele, I.I., Craske, L., Knight, C., Ferris, V., Njiru, Z., Hamilton, P., Lehane, S., Lehane, M. and Wendy, G. (2003) The Use of Specific and Generic Primers to Identify Trypanosome Infections of Wild Tsetse Flies in Tanzania by PCR. Infection, Genetics and Evolution, 3, 271-279. http://dx.doi.org/10.1016/S1567-1348(03)00090-X

[8] Adams, E.R., Malele, I.I., Msangi, A.R. and Gibson, W.C. (2006) Novel Species of Trypanosoma from Wild Tsetse Populations in Tanzania Identified Using Generic Primers to Amplify the ITS-1 Region. Acta Tropica, 100, 103-109. http://dx.doi.org/10.1016/j.actatropica.2006.10.002

[9] Swai, E.S. and Kaaya J.E. (2012) A Parasitological Survey for Bovine Trypanosomiasis in the Livestock/Wildlife Ecozone of Northern Tanzania. Veterinary World, 5, 459-464. http://dx.doi.org/10.5455/vetworld.2012.459-464

[10] Simarro, P.P., Franco, J.R., Gecchi, G., Paone, M., Diarra, A., Ruiz, P.J.A. and Jannin, G.J. (2012) Human African Trypanosomiasis in Non Endemic Countries (2000-2010). Journal of Travel Medicine, 19, 44-53. http://dx.doi.org/10.1111/j.1708-8305.2011.00576.x

[11] Kinung’hi, S.M., Malele, I.I., Kibona, S.N., Matemba, L.E., Sahani, J.K., Kishamawe, C. and Mlengeya, T.D.K. (2006) Knowledge, Attitudes and Practices on Tsetse and Sleeping Sickness among Communities Living in and around Serengeti National Park, Tanzania. Tanzania Health Research Bulletin, 8, 168-172.

[12] NBS (National Bureau of Statistics) (2008) Report on Tourism Trends in Tanzania. http://www.nbs.go.tz/

[13] Mlengeya, T.D.K., Muangirwa, C., Mlengeya, M.M., Kimaro, E., Msangi, S. and Sikay, M. (2002) Control of Sleeping Sickness in the Northern Parks of Tanzania. Proceedings of the 3rd Annual Scientific Conference of the Tanzania Wildlife Research Institute, Arusha, 3-5 December 2002, Vol. 35, 274-282.

[14] Steverding, D. and Troscianko, T. (2004) On the Role of Blue Shadows in the Visual Behaviour of Tsetse Flies. Proceeding of the Royal Society Biological Science, 271, 16-17. http://dx.doi.org/10.1098/rsbl.2003.0121

[15] Fe`vre, E.M., Picozzi, K., Jannin, J., Welburn, S.C. and Maudlin, I. (2006) Human African Trypanosomiasis: Epidemiology and Control. Advances in Parasitology, 61, 167-221. http://dx.doi.org/10.1016/S0065-308X(05)61005-6

[16] Brun, R., Blum, J., Chappuis, F. and Burri, C. (2010) Human African Trypanosomiasis. Lancet, 375, 148-159. http://dx.doi.org/10.1016/S0140-6736(09)60829-1

[17] Rayaisse, J.B., Esterhuizen, J., Tirados, I., Kaba, D., Salou, E., Diarrassouba, A., Vale, G.A., Lehane, M.J., Torr, S.J. and Solano, P. (2011) Towards an Optimal Design of Target for Tsetse Control: Comparisons of Novel Targets for the Control of Palpalis Group Tsetse in West Africa. PLoS Neglected Tropical Diseases, 5, e1332. http://dx.doi.org/10.1371/journal.pntd.0001332

[18] FAO (1982) Training Manual for Tsetse Control Personnel, Vol. 1, Rome, Italy.

[19] Challier, A. and Laveissiere, C. (1973) Un nouveau piege pour la capture des glossines (Glossina: Diptera, Muscidae): Description et essays sur le terrain. Cahiers ORSTOM, Series Entomologie Medical Parsitologie, 11, 251-262.

[20] Brightwell, R. Dransfield R.D., Kyoku, C., Golder, T.K., Tarimo, S.A. and Mungai, D. (1987) A New Trap for Glossina pallidipes. Tropical Pest Management, 33, 151-159. http://dx.doi.org/10.1080/09670878709371136

[21] Kaare, M.T., Picozzi, K., Mlengeya, T., Fèvre, E.M., Mellau, L.S., Mtambo, M.M., Cleaveland, S. and Welburn, S.C. (2007) Sleeping Sickness-A Re-Emerging Disease in the Serengeti? Travel Medicine and Infectious Disease, 5, 117124. http://dx.doi.org/10.1016/j.tmaid.2006.01.014

[22] Laohasinnarong, D., Thekisoe, O.M., Malele, I., Namangala, B., Ishii, A., Goto, Y., Kawazu, S.I., Sugimoto, C. and Inoue, N. (2011) Prevalence of Trypanosoma sp. in Cattle from Tanzania Estimated by Conventional PCR and LoopMediated Isothermal Amplification (LAMP). Parasitology Research, 109, 1735-1739. 
http://dx.doi.org/10.1007/s00436-011-2513-2

[23] Welburn, S.C., Maudlin, I. and Simarro, P.P. (2009) Controlling Sleeping Sickness-A Review. Parasitology, 136, 1943-1949. http://dx.doi.org/10.1017/S0031182009006416

[24] Malvy, D. and Chappuis, F. (2011) Sleeping Sickness. Clinical Microbiology and Infection, 17, 986-995. http://dx.doi.org/10.1111/j.1469-0691.2011.03536.x

[25] Leak, S.G.A., Peregrine, A.S., Mulatu, W., Rowlands, G.J. and D'leteren, G. (1996) Use of Insecticide-Impregnated Targets for the Control of Tsetse Flies (Glossina spp.) and Trypanosomiasis Occurring in Cattle in an Area of South-West Ethiopia with a High Prevalence of Drug-Resistant Trypanosomes. Tropical Medicine and International Health, 1, 599-609. http://dx.doi.org/10.1111/j.1365-3156.1996.tb00085.x

[26] Malele, I.I. (2011) Fifty Years of Tsetse Control in Tanzania: Challenges and Prospects for the Future. Tanzania Journal of Health Research, 13, 1-10.

[27] Ripamonti, D., Massari, M., Arici, C., Gabbi, E., Farina, C., Brini, M., Capatti, C. and Suter, F. (2002) Brief Report, African Sleeping Sickness in Tourists Returning from Tanzania: The First 2 Italian Cases from a Small Outbreak among European Travellers. Clinical Infectious Diseases, 34, 18-22. http://dx.doi.org/10.1086/338157

[28] Gautret, P., Clerinx, J., Caumes, E., Simon, F., Jensenius, M., Loutan, L., Schlagenhauf, P., Castelli, F., Freedman, D., Miller, A., Bronner, U. and Parola, P. (2009) Imported Human African Trypanosomiasis in Europe, 2005-2009. Euro Surveillance, 14, Article ID: 19327. http://www.eurosurveillance.org/ViewArticle.aspx?ArticleId=19327

[29] Gobbi, F. and Bisoffi, Z. (2012) Human African Trypanosomiasis in Travellers to Kenya. Euro Surveillance, 17, Article ID: 20109. http://www.eurosurveillance.org/ViewArticle.aspx?ArticleId=20109

[30] Alibu, V.P., Enyaru, J.C.K., Matovu, E., Malele, I.I., Chisi, J.E., Mbongo, N., Mansinsa, P., Intisar, E.R., Mohammed, Y., Abdelrahman, M.M., Ochi, E.B. and Lukaw, Y.S. (2015). Molecular Xenomonitoring of Trypanosomes in Tsetse Flies. Journal of Parasitology and Vector Biology, 7, 108-114.

[31] Sindato, C., Malele, I.I., Mwalimu, C., Nyingilili, H.S., Kaboya, S., Kombe, E., Msumary, C. and Manoza, A. (2007) Seasonal Variation in Human African Trypanosomiasis in Tarangire National Park in Babati District, Tanzania. Tanzania Health Research Bulletin, 9, 136-139. http://dx.doi.org/10.4314/thrb.v9i2.14317

[32] Bekele, J., Asmare, K., Abebe, G., Ayelet, G. and Gelaye, E. (2010) Evaluation of Deltamethrin Applications in the Control of Tsetse and Trypanosomosis in the Southern Rift Valley Areas of Ethiopia. Veterinary Parasitology, 168, 177-184. http://dx.doi.org/10.1016/j.vetpar.2009.11.028 